\section{New Sections and Chapters Recognized at Fall Meeting}

Six new MRS Student Chapters and four Sections received charters during the Plenary Session held Wednesday evening, December 4, during the Fall Meeting. Kathleen Taylor, 1985 MRS Second Vice President, presided over the presentation of charters to the six Student Chapters formed in 1985. MRS President Gordon Pike made the following charter presentations:

- Cornell University, Glenn Harmon, chapter president

- Rensselaer Polytechnic Institute, Steve Bilodeau, chapter president

- Massachusetts Institute of Technology, Mary L. Manger, chapter chairperson

- Pennsylvania State University, Paul Sliva, chapter president

- Research Triangle Universities, Cheryl Dale, chapter vice president (accepting for Nicholas Biunno, chapter president)

- Carnegie-Mellon University, Thomas M. Rask, chapter president

Taylor explained that the Research Triangle Universities Chapter includes University of North Carolina at Chapel Hill, University of North Carolina at Charlotte, North Carolina State University, Duke University, Durham Technical College, and North Carolina A\&T. This Chapter was formed from the large student representation within the North Carolina Section.

The new chapters join the already established chapters at UCLA, University of Pennsylvania, and Case Western Reserve University.

MRS Secretary Rod Ewing recognized the formation of four new MRS Sections. Charters were presented by Gordon Pike to:

- Western New York Section, M. Gupta, Eastman Kodak

- North Texas Section, Russell Pinizzotto, Ultrastructure, Inc.

- New Mexico Section, Harold Anderson, University of New Mexico

The Southern California Section will receive its charter at the 1986 Spring Meeting in Palo Alto. These new sections join established sections in North Carolina and Northern California.

The growing contingent of MRS groups in the local industrial research and academic communities are planning a variety of events. See reports on activities of the North Carolina Section, Southern California Section, RPI Student Chapter and Cornell University Student Chapter in this issue of the BULLETIN. And look for reports in upcoming issues.

\section{Interested in organizing}

\section{an MRS Student Chapter}

or Section in your area?

\section{Contact MRS Headquarters}

for information.

Telephone (412) 367-3003

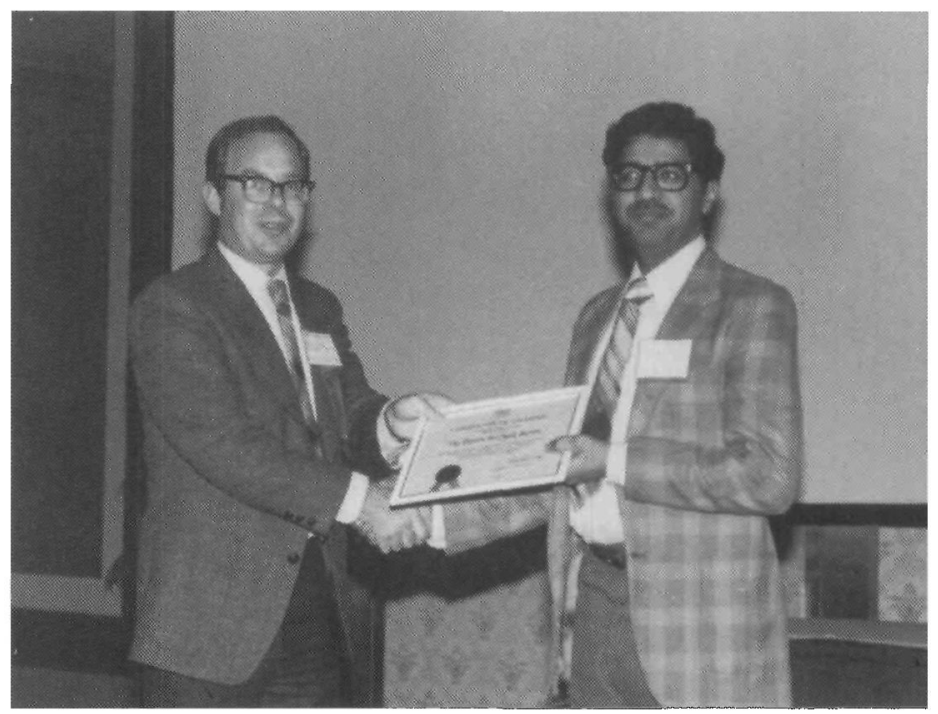

M. Gupta (right) receives Western New York Section charter from Gordon Pike.

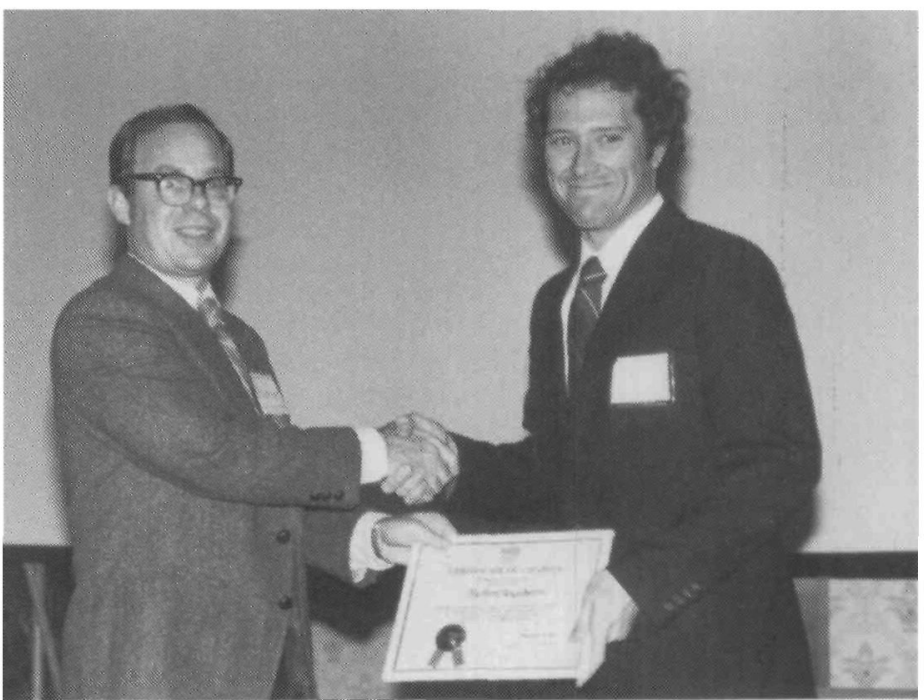

Russell Pinnizotto (right) receives North Texas Section charter from Gordon Pike.

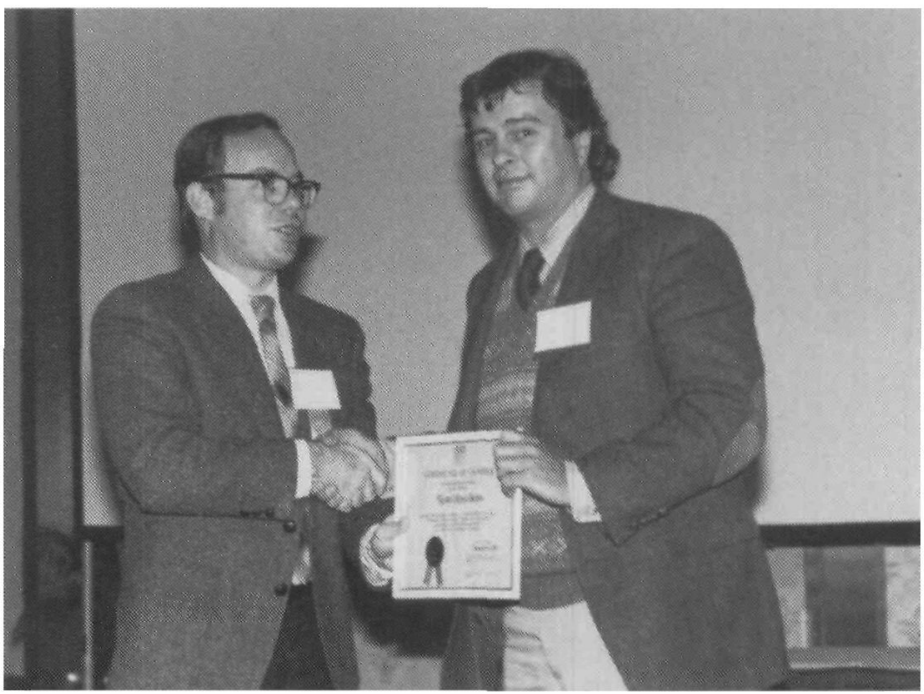

Harold Anderson (right) receives New Mexico Section charter from Gordon Pike. 


\section{LOCAL SECTION NEWS}

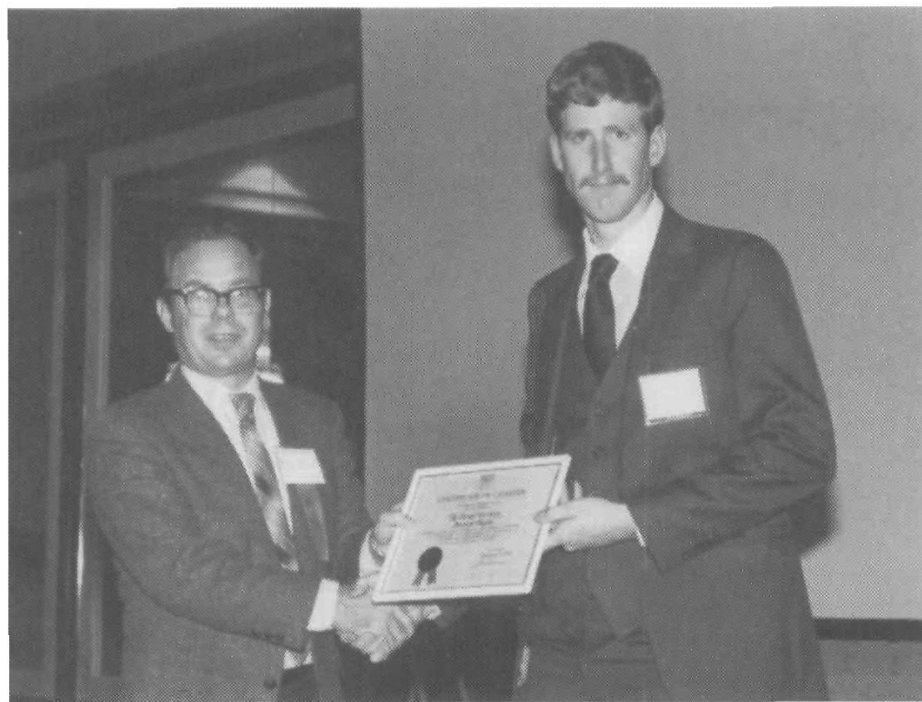

Glenn Harmon (right) receives Cornell University Student Chapter charter from Gordon Pike.

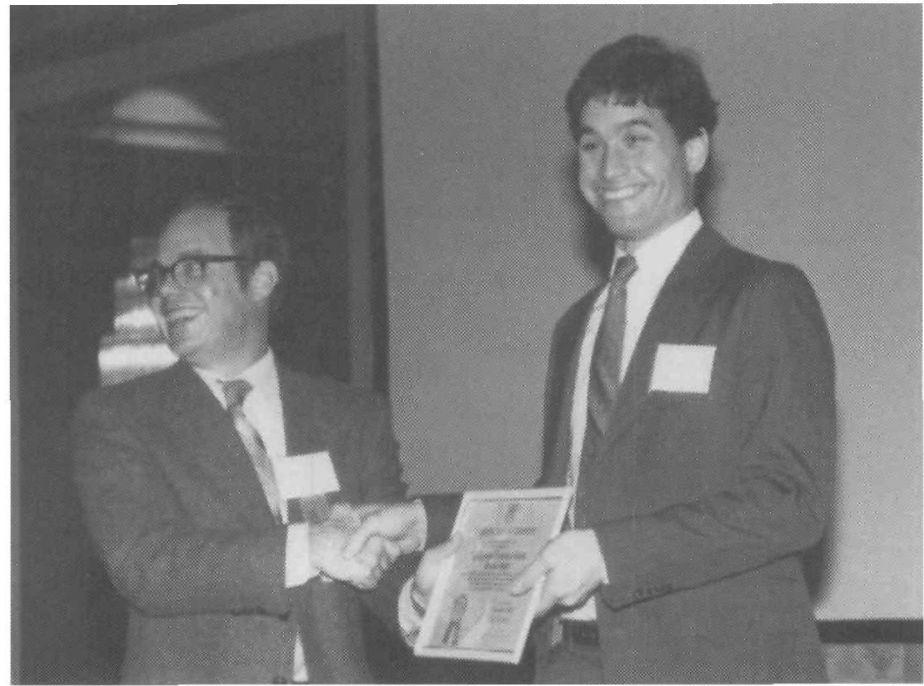

Steve Bilodeau (right) receives Rensselaer Polytechnic Institute Student Chapter charter from Gordon Pike.

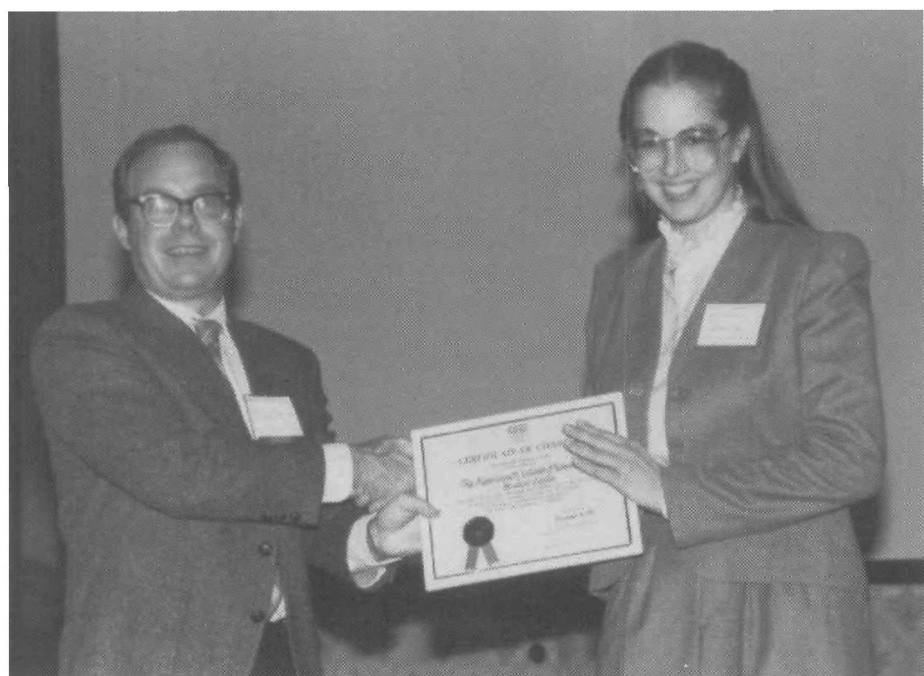

Mary Manger (right) receives Massachusetts Institute of Technology Student Chapter charter from Gordon Pike.

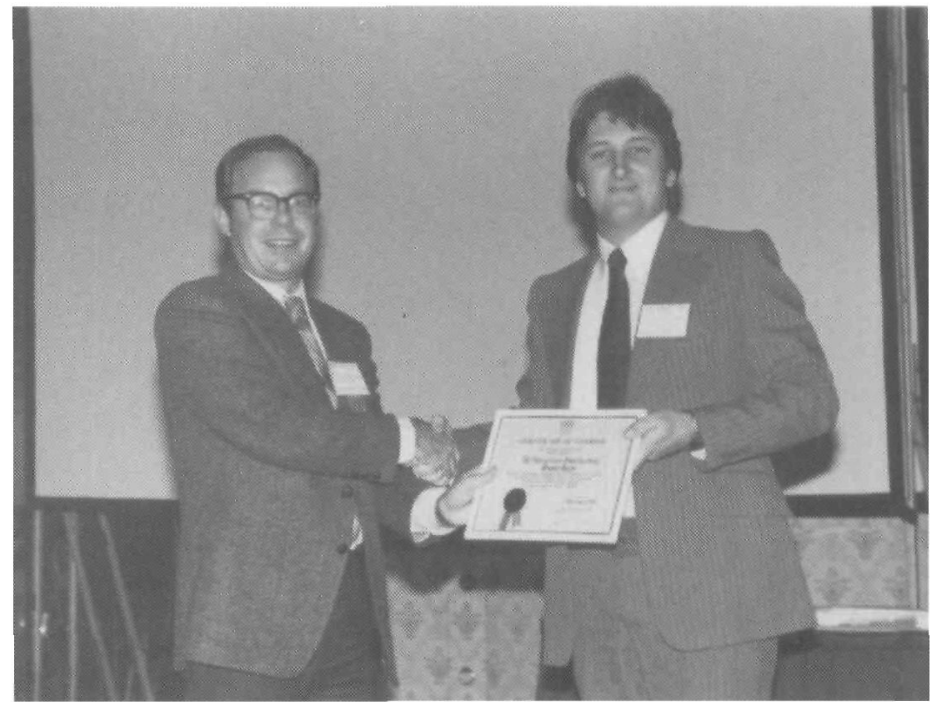

Paul Sliva (right) receives Pennsylvania State University Student Chapter charter from Gordon Pike.

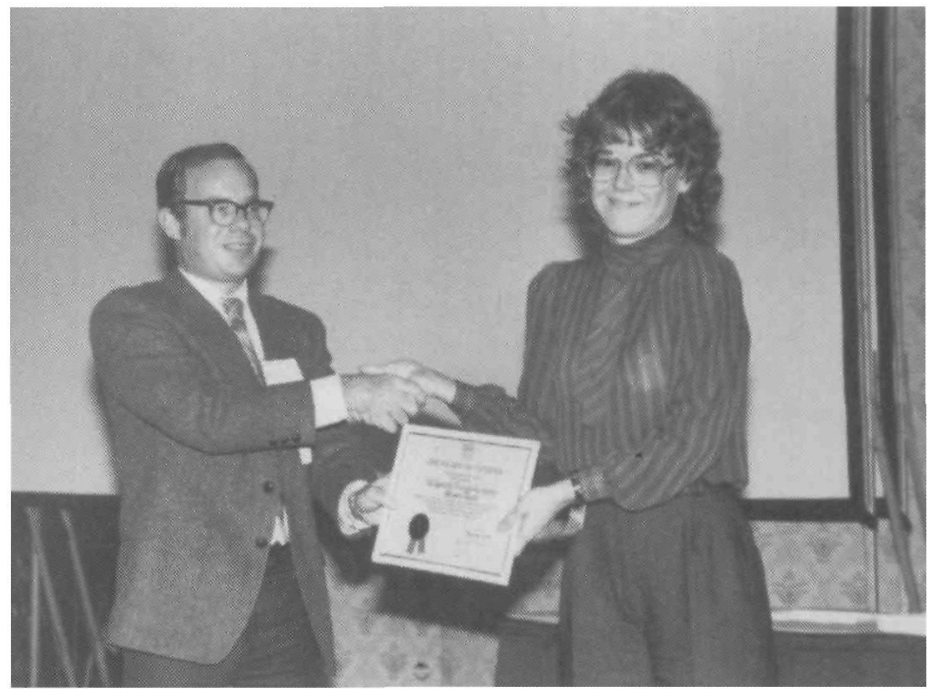

Cheryl Dale (right) receives Research Triangle Universities Student Chapter charter from Gordon Pike.

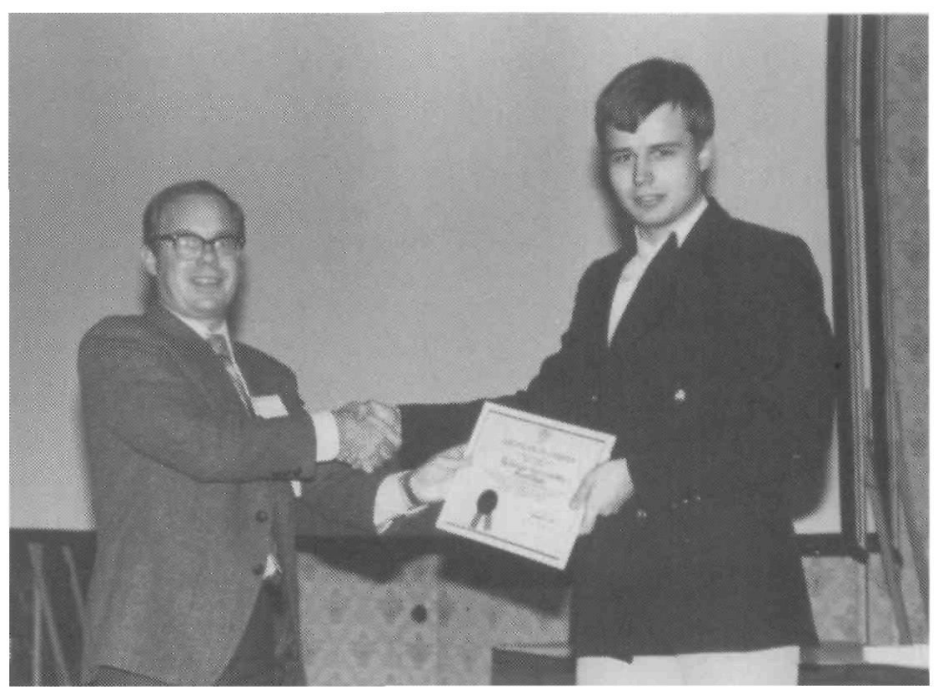

Thomas Rask (right) receives Carnegie-Mellon University Student Chapter charter from Gordon Pike. 